\title{
De la comunión política a la fragmentación estatal: crimen, ley y soberanía en Carlos Fuentes y Juan Rulfo.
}

\section{From Political Unity to State Fragmentation: Crime, Law and Sovereignty in Carlos Fuentes and Juan Rulfo.}

\begin{abstract}
Resumen
El autor utiliza la última novelística del escritor mexicano Carlos Fuentes para pensar en el sistema político mexicano y sus transformaciones. Además, utiliza la figura de Pedro Páramo como un ejemplo de soberanía total en comparación con la fragmentación gubernamental y las formas plurisoberanas que Carlos Fuentes utiliza en sus novelas para demostrar cómo las transformaciones del Estado mexicano han operado: de un aparato estatal fuerte a un gobierno fragmentado y abatido por otras formas de control, como la globalización, el crimen y el necroempoderamiento.
\end{abstract}

Palabras claves poder, México, violencia, globalización, literatura mexicana.

\begin{abstract}
The author analyzes the late work of Mexican writer Carlos Fuentes to think about the Mexican political system and its transformations. Also, the author uses the figure of Pedro Paramo as an example of total sovereignty in comparison with the state fragmentation and the multi-sovereign forms that Carlos Fuentes uses in his novels as tools to demonstrate how the transformations have operated in Mexico: from a strong state to a fragmented government surrounded by other forms of control such as globalization, crime, and necroempowerment.
\end{abstract}




\section{El carnaval del poder}

El convulso periodo político mexicano del siglo $\mathrm{XX}$ - o más bien su estática temporalidad estatal-inmunizó los proyectos políticos de cambio y sus aspiraciones democráticas sexenales, especialmente porque su metamorfosis política operó y sigue operando solo en la superficie. Resulta normal, pues, que de la historia de autoritarismos y hombre fuertes — siendo Porfirio Díaz, acaso, una premonición terrible de un sistema inamovible - surgiera una novela que nos habla a la cara del poder soberano establecido simultáneamente como emergencia y normalidad democrática. La escritura de Pedro Páramo y la interpretación que le demos al hombre fuerte de Comala, sentado en un banquete de sombras, nos llevará a caracterizarlo como la personificación de un Estado que, durante buena parte del siglo XX e interrumpido por la Revolución y su posterior domesticación, clausuró las formas democráticas de la pluralidad para presentarlas bajo el mantra de la estabilidad y el progreso controlados. Pedro Páramo es, pues, el Estado que se niega a cambiar cambiando: la metamorfosis de una piedra. Pedro: la roca fundacional de una vida de muerte; Páramo: en medio de un desierto de murmullos.

Alejadísimo de la fatuidad política del presente y sus formas teledirigidas y cosméticas, Pedro Páramo navega el tiempo de las quimeras políticas en donde todo se le debe a una cabeza y en donde esta dictamina las formas del cuerpo. El señorío vertical transformado en disciplina social, económica y legal. Una forma de dominación en donde la soledad y sequedad de los eriales de Comala y también sus habitantes se vuelven imperio de humo y tiempo anclado: localizados entre jaurías fragmentadas - México, la Revolución-, lo único que les queda es el desorden de su memoria. Comala: no un infierno, una forma de ejercer el poder; Comala: excepto el de Pedro Páramo, todos los poderes defenestrados.

Esta novela de medio siglo contrasta con la representación política que el escritor Carlos Fuentes hizo de los nuevos focos de poder que conviven con el Estado mexicano en la actualidad. Si la primera novelística de Carlos Fuentes se 
CATEDRAL Tomada: Revista de crítica literaria latinoamericana / Journal of Latin American Literary Criticism De la comunión política a la fragmentación estatal: crimen, ley y soberanía en Carlos Fuentes y Juan Rulfo.

caracterizó por una visión más constructivista del futuro, en sus últimas novelas vemos el carnaval político, la desintegración y los flujos rebeldes del mundo contemporáneo convivir con los otrora caciques nacionales: el PRI y las instituciones que ayudó a formar. No solo eso: Carlos Fuentes demuestra que las formas de necroempoderamiento se hacen cada vez más visibles al enquistarse en instituciones de diversa importancia dentro del sistema, como las grandes compañías transnacionales o las futuras fortunas de la clase media. El entrelazamiento entre capitalismo y crimen es una de las tesis principales del escritor mexicano, que demuestra cómo la convivencia - y connivencia- de legalidad e ilegalidad es posible y hasta encomiable en un sistema en el que los sujetos marginados se convierten en verdaderos poderes públicos que controlan territorios a través de técnicas de violencia especializadas, convirtiendo los espacios de su dominación en los que operan las diversas bandas criminales en anomias legales y emergencias sociales. La violencia transforma la condición trashumante de la población en verdaderos refugiados que necesitan desplazarse para salvar la vida.

El interés del escritor mexicano Carlos Fuentes alrededor de la pregunta por el poder es largo y vasto como su obra: las innumerables opiniones, artículos, entrevistas y ensayos que el novelista dio a lo largo de su vida vuelven articuladas en una mezcla de espanto y admiración por lo que la política podía hacer por los pueblos. La esperanza que Fuentes tenía en el Estado para ofrecerle a México, en bandeja de plata, las llaves del progreso y las promesas de la Revolución a partir de la sagrada entraña de la Presidencia lo llevó a aliarse, por ejemplo, con el Presidente Luis Echeverría: "Given, moreover, the enormous powers vested in the president and the consequent belief that only the president can bring about significant changes in Mexico, it is not surprising that Fuentes have allied himself with Echeverría [...]" (Van Delden 120).

La ilusión que Fuentes tenía en el Estado la vertió, según Van Delden, en un artículo que el escritor publicó por aquella época, "Operaciones críticas en el verano de nuestro descontento" (1972), en donde promovió la idea de que México 
necesitaba un Estado fuerte. El escritor, el político: el Fuentes paradójico situado entre las viejas formas políticas de la Revolución y la estética de vanguardia de su obra. Esto lo llevó a una contradicción que Van Delden identifica a partir de la diferencia entre el mundo político y el mundo literario: al poner su confianza en Echeverría, Carlos Fuentes se distanció de la "dimensión utópica" (139) en la que estaba inspirado su trabajo: "Terra Nostra proposes a clear thesis about the nature and origins of Spanish American culture: in brief, the notion that it possesses at its source a democratic, pluralist, and utopian dimension that it must struggle to recapture" (Van Delden 139).

Basta leer las últimas obras de Carlos Fuentes para darnos cuenta que la visión utópica, su fe en el Estado mexicano y su capacidad para articular desde el poder la respuesta política de la nación, se convirtieron en débiles comparsas y apostillas y trazos anémicos de una continuidad mucho mayor: la del crimen, la de la globalización, la de la corrupción y la farsa política como últimos derroteros del poder. Obras como La silla del águila (2003), Adán en Edén (2009) y sobre todo La voluntad y la fortuna (2008) atestiguan que la nueva utopía no es ya la de Tomás Moro, sino la utopía del crimen y las complejas formas de su convivencia en las junglas democráticas del nuevo siglo. Con razón: si, según Gareth Williams, la modernidad mexicana fue construida a partir de un "estado total" (12) que a ratos buscaba acabar con la división entre Estado y sociedad, en $L a$ voluntad y la fortuna encontramos un Estado totalmente fragmentado que lejos de la razón universalizada del priismo y su proyecto está ante una serie de discursos que irrumpen en su vitalidad política y la socavan. Ya no más soberanía: solo fiesta; adiós al control estatal de la corrupción: ahora solo crimen; buenos tiempos aquellos en donde la palabra del Presidente rebotaba en las paredes vacías del palacio: ahora la cacofonía representa la nueva dimensión plurisoberana. Este movimiento crítico y pesimista de Carlos Fuentes lo encontramos en sus últimas obras a partir, según Steven Boldy, de Cristóbal Nonato (1987) y cuyos representantes incluyen, además de las obras ya señaladas, a La frontera de cristal (1995). Para Boldy: 
CATEDRAL TomadA: Revista de crítica literaria latinoamericana / Journal of Latin American Literary Criticism De la comunión política a la fragmentación estatal: crimen, ley y soberanía en Carlos Fuentes y Juan Rulfo.

En términos generales, estos textos exhiben una preocupación pesimista por la degeneración de la vida social y política mexicana. La conciencia trágica o irónica que en los textos clásicos de Fuentes medió entre el idealismo y el fracaso histórico es reemplazada por la farsa criminal. (244)

En estas últimas novelas se mezclan el horror y la desemejanza, el espejo deformado después de haber sido exhumado: una especie de apocalipsis verbal y narrativo en donde se dinamita la formalidad política, el decoro nacional, las posibilidades de un futuro. Ahora, el nuevo paradigma es el de descubrir al crimen y al poder económico como los nuevos actores que, en la búsqueda por su propia utopía, generan un caos en el corazón del Estado: el Presidente Valentín Pedro Carrera en La voluntad y la fortuna es un mero títere que, comparado con el poder ilimitado e insalubre de Pedro Páramo - en cuya figura encontramos una anomalía legal en donde el poder trasforma el crimen en ley-, apenas alcanza a superar las esquelas tristes de su narcisismo e intrascendencia frente a otro poder que claramente lo avasalla: aquel del nuevo cacique moderno económico, Max Monroy, una parábola, si se me permite, de Carlos Slim, uno de los hombres más ricos del mundo que, al igual que Monroy, construyó su imperio a partir de las telecomunicaciones. La ambigüedad de ambas figuras respecto a su contenido democrático llevan a Fuentes, en La voluntad y la fortuna, a preguntarse acerca de las formas ambiguas de los nuevos caciques que varían sus geometrías a partir de caprichos privados, beneficios económicos o estrategias transnacionales sin ningún tipo de consideración pública: “¿Era, en fin, Max Monroy el emblema del autoritarismo más cerrado o de la democracia más expansiva?” (Fuentes 4067).

Max Monroy representa la utopía de darles a los ciudadanos de México un celular para unirse con los demás, para no estar desconectados, para estar informados siempre: "La distopía globalizada y posmoderna de Monroy, donde la libertad consiste en que cada ciudadano tenga una especie de iPhone nacional, no 
tiene remedio ni admite réplica ya que se ha disfrazado de Utopía" (Boldy 250). Max Monroy: un poderoso empresario que le puede ordenar al presidente que permanezca sentado mientras Monroy permanece de pie. Valentín Pedro Carrera: el presidente bajo el cual Jericó, otro personaje de la novela, desarrolla una conspiración bajo sus narices; Valentín Pedro Carrera, personificación de la ley parlanchina y débil al que solo se le ocurre hacer festejos para saciar las tensiones del pueblo.

Lejos quedan, en esta novela, cualquier poder vertical que emane del Estado mexicano. Lejos también quedan, por ejemplo, los artículos 145 y 145 bis de "disolución social" del código penal mexicano que condenaban a un grupo de 3 o más personas que se juntaran para discutir ideas que pudieran socavar el orden soberano a una pena de 2 a 12 años de prisión: estos dos artículos pueden ser considerados la apoteosis soberana y el pináculo de la excepción ejecutiva del Estado mexicano y la formación del PRI como partido nación, los cuales representan la articulación política de la ley y la articulación legal de la política dentro del corazón de la autoridad. Lo primero, como una manera de formalizar y continuar el pacto político establecido después de la Revolución entre la clase política que decidía, finalmente, cuáles reglas serían aplicadas como resultado de una negociación política entre ellos mismos, convirtiendo a la ley en embrión revolucionario y en pacto político; lo segundo, para darle a esa estructura política nacional -el PRI - un soporte legal a sus operaciones. Al volverse depositarios y legatarios de la Revolución y de la modernidad mexicana, el PRI se convirtió en un fantasma ingobernable. En La voluntad y la fortuna encontramos una frase que bien puede resumir todo el aparato político mexicano del siglo XX: "El poder se origina en el poder, no fuera de él, como una célula se forma dentro de otra" (Fuentes 6335).

El PRI aprendió a cooptar, intimidar, suprimir pero, sobre todo, a contorsionarse ante las demandas políticas de organizaciones y partidos que buscaban un aliento en el sistema. Como régimen autoritario-clientelarburocrático, el PRI otorgó, mediante sucesivas reformas electorales (1963, 1972 y 
CATEDRAL TOMADA: Revista de crítica literaria latinoamericana / Journal of Latin American Literary Criticism De la comunión política a la fragmentación estatal: crimen, ley y soberanía en Carlos Fuentes y Juan Rulfo.

1973) y una importante reforma política (1977), una intermitente llamarada de cambio. Aquel era un sistema con Constitución, leyes, reglamentos y procesos, pero no una democracia: orbitaban en rededor de ésta última como concepción formal pero estaban más cerca de un régimen autoritario. Con la participación marginal de ciertos actores políticos ajenos al régimen y algunos espacios de reflexión y de crítica, el partido aseguró un mandato fuerte sobre garantías fantasmas. Fueron las crisis económicas, el simbolismo del 68, el fortalecimiento en la periferia de otros partidos - especialmente el PAN_- la apertura de México hacia el exterior y la presión social de ciertos sectores -intelectuales, estudiantes - lo que provocó que los cimientos del partido único se desmoronaran sin que esto impidiera que el atavismo del régimen nos fuese heredado y también las nuevas formas de encubrimiento, presentes, sobre todo, en la política estatal mexicana aunque también a nivel federal. Así, el PRI aseguraba su supervivencia en forma de condicionantes: un régimen con partidos políticos que no permitía espacios de victoria y ni siquiera el atisbo de la misma pero que sanaba esas heridas con reformas que causaban escozor y esperanza en ciertos sectores pero nunca el propio derroche de los mismos. El legado más directo de esta forma de gobernar lo encontramos en la fragilidad del pacto estatal con otros sectores y agentes que han cobrado vida a expensas del poder. En su afán por abrirse para legitimarse, el PRI dinamitó los pactos sin darse cuenta que había sido superado por los acontecimientos. Llegó el año negro de 1994. Llegó una nueva fuerza política al país en el año 2000. Ya no se cumplía eso que Van Delden escribió y que llevó a Fuentes a querer aliarse con el poder: "On the one hand, the state acts to concentrate power in the hands of the few; on the other hand, the state is the only force that can provide for a more equitable distribution of economic resources in Mexico" (Van Delden 123).

La voluntad y la fortuna es una novela sorprendentemente densa comparada con La silla del águila o Adán en Edén: la historia gira en torno a Josué y Jericó, dos adolescentes que se conocen en la escuela y que comparten algo más que la letra inicial de su nombre: lecturas, mujeres, experiencias. 
Además, cada uno recibe un cheque mensual de un benefactor anónimo. Fuentes nos guía por sus vidas como si ambos fuesen espejos uno del otro y los llega a comparar con Cástor y Pólux, sobrenombre impuesto por su maestro de filosofía Filópater, algo así como "padre amoroso": "La alusión mitológica no se nos escapó y tanto Jericó como yo, al instante, nos miramos sabiendo que hablaba de los gemelos nacidos del mismo huevo pues su padre era un Dios disfrazado de cisne" (Fuentes 440).

Josué y Jericó, al entrar a la universidad, se separan: Josué irá a la escuela de leyes mientras Jericó parte al extranjero. La novela, a partir de ese momento, baja en un espiral en donde los eventos se densifican, los personajes multiplicados arrostran y resisten distintas formas de poder únicamente para encontrarse cara a cara con el crimen impune, la maldad indiferente, el rezago existencial. Aparecerán, entonces, personajes como Miguel Aparecido, un preso de la cárcel de San Juan de Aragón, simbólicamente situada debajo de la ciudad de México, el cual permanece en la cárcel por voluntad propia. Josué, como parte de sus prácticas de Derecho y enviado por el poderoso licenciado Sanginés, tendrá que descubrir el secreto de Miguel Aparecido.

Josué conocerá (¿o rescatará?) a Lucha Zapata, una mujer en una deriva existencial compuesta de alcohol y drogas. También regresará a la casa de Errol Esparza, un amigo de la infancia, cuyo padre, Nazario Esparza, es un hombre con pocos escrúpulos, arribista y decadente: típico representante de una clase social que, con tal de llevarse parte del pastel, no duda en relacionarse con el crimen y la impunidad. Vendrán personajes como Sara P. la nueva esposa de Nazario Esparzan, la cual, junto con una banda dirigida por el mariachi Maxi Batalla asesinaron a la primera esposa de Esparza ${ }^{1}$. Josué, por orden del licenciado Sanginés, irá a trabajar con Max Monroy; Jericó, de vuelta de su viaje por el extranjero, irá a la Presidencia de la República, en donde conspirará contra el Presidente y utilizará a los presos de la cárcel de San Juan de Aragón para tomar

${ }^{1}$ No dude el lector en considerar ciertos aspectos de esta nueva novelística como paródicos o grotescos. Fuentes parece moverse entre la certeza de la realidad como ficción y el de la imaginación política desterrada como nuevo paradigma. 
CATEDRAL TOMADA: Revista de crítica literaria latinoamericana / Journal of Latin American Literary Criticism De la comunión política a la fragmentación estatal: crimen, ley y soberanía en Carlos Fuentes y Juan Rulfo.

el Zócalo y la ciudad de México. Se topará con la alianza inesperada entre el presidente Valentín Pedro Carrera y Max Monroy, los cuales le cierran al motín organizado por Jericó cualquier posibilidad de éxito. Al final de la novela descubrimos que Asunta Jordán, la eficiente y frívola secretaria personal de Max Monroy, elimina a Josué y Jericó, que descubrimos son hermanos, para convertirse en heredera directa del magnate - o al menos intentarlo- Sabemos desde el principio que Josué está muerto - de hecho, su cabeza cortada es la que narra la historia ${ }^{2}$ - y a lo largo de la novela, en una especie de anacoluto narrativo o reiteración macabra, la cabeza nos recuerda que es cabeza separada del cuerpo para siempre: el lector no puede dejar de pensar en la alegoría que representa la separación del cuerpo del Estado con la cabeza, es decir, la Presidencia de la República al mando del débil Presidente Valentín Pedro Carrera. Recuerde el lector que en La silla del águila el Presidente Lorenzo Terán es un hombre también débil y son más bien sus colaboradores los que toman las decisiones, actúan y buscan conseguir el poder de la silla presidencial. Es como si Carlos Fuentes, en estas últimas novelas, creyera que el poder en México había topado con un muro y una serie de tentáculos que lo aprisionaban. Mientras que en $L a$ silla del águila el Presidente es representado, hacia dentro de su gabinete, como un hombre débil, en La voluntad y la fortuna el Presidente es situado, hacia afuera, en una órbita de intrascendencia respecto a Max Monroy.

Al igual que en la guerra contra el narcotráfico iniciada por Felipe Calderón y en la cual según Williams “...there is no fully schematized or negotiable distinction in place between friend and enemy, war and peace, aggressor and victim, law and civil war" (Williams 153), en La voluntad y la fortuna la indistinción entre crimen y ley la representa Jericó: instalado en el corazón del poder, es decir, la Presidencia de la República, Jericó utiliza los

2 Podemos pensar que el gesto es significativo a otro nivel: la cabeza cortada que habla para recuperar las voces de las víctimas de la guerra contra el narcotráfico no me parece una exageración. Una lectura de Pedro Páramo puede ir en torno también a esta idea: los murmullos y los ecos de Comala son una alusión a las voces de las víctimas de la Revolución pero también del poder estatal mexicano en la primera mitad del siglo XX. 
medios del Presidente contra el propio Presidente para convertir su motín personal en empresa nacional utilizando a los criminales de San Juan de Aragón, convenientemente situada debajo de la ciudad de México: vemos aquí una simbolismo muy apropiado para hablar de la indistinción entre crimen y ley, casi como si Fuentes nos dijera que los ríos profundos de la sociedad mexicana se encuentran disfrazados en las dinámicas criminales que buscan y muchas veces logran penetrar los cauces legales y morales para presentarse como ideal.

Si el motín nacional de Jericó no llega a buen puerto, a nivel narrativo, es por la alianza entre los dos poderes de la novela (Monroy y Carrera); si no lo logra, a nivel escritural, es porque Fuentes parece indicarnos que ya no hay Revolución, fractura o ilusión sino acaso inercia, complacencia y senectud ¡Qué lejos queda el Fuentes memorioso, esperanzado, casi quimérico! "Sí, sí, sí. Creo en la capacidad de sobrevivencia de mi país. México tiene un gran talento para la sobrevivencia” (Hernández 95).

Recuerde el lector una de las tantas conversaciones entre Josué y Jericó, bastante reveladora porque marca la intersección que atraviesa vida y crimen con una brutalidad que la engarza con la escasez de las posibilidades para escapar, para darse cuenta que la hegemonía estatal es fábula del pasado en donde el Estado ni siquiera aparece como posibilitador o lubricante social. Casi como si la voluntad de los poderes se encadenara, siniestros, con la fortuna como epifanía superior de una tragedia mexicana particular, Josué nos recuerda respecto a Jericó:

Dijo que la vasta masa pauperatis de la Ciudad de México no tenía más opción que la pobreza o el crimen. ¿Cuál prefería él? Sin duda, la criminalidad. Me miró fijamente, como cuando hacíamos el amor con la mujer tatuada. La pobreza podía ser una consolación. El peor lugar común del sentimentalismo, añadía, separando sus manos de las mías, era creer que los pobres son buenos. No era cierto: la pobreza es el horror, los pobres son malditos, malditos por su sumisión a la fatalidad y 
CATEDRAL TOMADA: Revista de crítica literaria latinoamericana / Journal of Latin American Literary Criticism De la comunión política a la fragmentación estatal: crimen, ley y soberanía en Carlos Fuentes y Juan Rulfo.

sólo redimibles si se rebelan contra su miseria para convertirse en criminales. El crimen es la virtud de la pobreza, dijo en esa ocasión que no olvido Jericó, bajando la mirada y retomando mis manos antes de sacudir la cabeza [...]. (Fuentes 1319)

El Estado en La voluntad y la fortuna no averigua nada, no resuelve nada: todo lo aplaza, todo lo frivoliza, se trata de la manifestación de un poder que se queda sentado, como Pedro Páramo, solo que en este caso nada sucede: el país sigue funcionando gracias a los polos económicos de los nuevos potentados (Monroy/Slim) y a los del crimen (Maxi Batalla, Sara P., Asunta Jordán, Jericó). El Estado deviene inoperante gracias al bombardeo informativo que lo coloca como cómplice del crimen y muy atrás de la innovación que representa la nueva empresa mundial. El nuevo cacique ya no se identifica con el poder político estatal sino con el de la creatividad empresarial que todo lo abarca: al igual que Pedro Páramo, Max Monroy parece ser padre de todos, dador de vida, que toma mujeres, contratos, leyes, poder. El propio presidente Valentín Pedro Carrera lo sabe cuándo le dice a Jericó que Monroy ha llevado la información "a los rincones más alejados" (Fuentes 2925) y que antes "uno podía gobernar casi en secreto, la gente se creía el informe anual del primer de septiembre..." (2925). La nostalgia por el poder: de eso viven los presidentes mexicanos Lorenzo Terán y Valentín Pedro Carrera. A este último le interesa, en lugar de la formalidad tradicional de la política y su lambisconería, un festín de trivialidades o, en palabras de Fuentes: “Hoy, Josué, el gran drama de México es el que el crimen ha sustituido al Estado. El Estado desmantelado por la democracia cede hoy su poder al crimen auspiciado por la democracia” (Fuentes 6499).

La transición en la novelística de Carlos Fuentes nos revela el desencanto que sentía el escritor por las posibilidades del poder en México para siquiera sugerir una transformación no ya que incluyera a todos los sectores sociales y empresariales del país, sino apenas para renovar sus propios vicios. En una entrevista en la Universidad de California en Los Ángeles en 1980, Fuentes 
confiaba en México como una potencia que en el futuro jugaría un rol preeminente. Sus últimas novelas parecen reflejar lo contrario:

Creo que México ha adquirido un peso específico, una importancia específica. Tiene una larga tradición de relaciones exteriores, de la construcción de una nacionalidad y de un Estado nacional, y está preparado para jugar un importante papel en este nuevo mundo multipolar y de autoconfianza, no autosuficiencia (Hernández 107).

\section{Pedro Páramo: el anti cacique}

Trazar una línea de la gravedad política y su densidad en Pedro Páramo a las formas risibles y débiles del Estado en La voluntad y la fortuna me parece una comparación afortunada para repensar en el mapa político mexicano y sus múltiples y poliédricas transformaciones. La aglomeración del poder en Pedro Páramo pasa por la oralidad: no hay nada escrito, excepto la voluntad de Pedro Páramo para asolar Comala y absorberlo todo. Y es que, como Williams nos recuerda, Pedro Páramo es la figuración del más fuerte que "ha ganado sobre todo" (19):

$\mathrm{He}$ is the embodiment of a profoundly contradictory tendency within the extension of the town's relation to accumulation, for he represents the extension of one of the principle values of bourgeois society but in reality sustains feudal social bonds as the only telos for Comala's individualized accumulation of wealth. (19)

Es verdad: una lectura lógica de Pedro Páramo nos lleva a ver a su personaje principal como un cacique soberano que decide sobre todo. El problema 
CATEDRAL TomadA: Revista de crítica literaria latinoamericana / Journal of Latin American Literary Criticism De la comunión política a la fragmentación estatal: crimen, ley y soberanía en Carlos Fuentes y Juan Rulfo.

es que la representación de Pedro Páramo como cacique podría aparecer, desde cierto punto de vista, históricamente problemática.

In her study of agrarian societies in the Puebla region of Mexico, Luisa Paré $[\ldots]$ notes that the encounters between capitalist and non-capitalist modes of production in rural areas frequently call for the introduction of an agent of mediation, a third term which would negotiate between systems and through which their conflicting demands could pass. (Dove 97)

Al México rural, continúa Dove más adelante, le correspondió la figura del cacique: un depósito de la "tradición" al mismo tiempo que un "facilitador de la modernidad" (98). Al final de ese párrafo el autor llega a decir que el cacique es una figura de traducción en sí misma. Si el cacique, como mediador, es una figura traductora, si esto es así, ¿qué traduce, qué facilita Pedro Páramo en la novela? Gareth Williams ve en Pedro Páramo a un representante de los valores burgueses que en realidad sostiene "lazos sociales feudales" (19): es decir, se trata de una figura contradictoria que amasa bienes de manera primitiva: "Pedro Páramo doesn't become a landowner simply because he is anti-modern or archaic, but rather because this is his historical role during a moment of intense primitive accumulation (Beckman 818).

Pedro Páramo no media entre Estado y comunidad, tampoco entre modernidad y tradición. Pedro Páramo suspende a Comala en el tiempo y la deja paralizada. No hay un ir hacia adelante ni tampoco un ir hacia atrás: los ecos y murmullos son representaciones de un circuito y una geometría cerrada sobre sí misma que se repite interminablemente. Comala está atrapada en sí misma. Pedro Páramo no es un cacique (mediador) arquetípico sino acaso uno trascendental o casi mítico: una burbuja mortal y vital al mismo tiempo que mantiene suspendidos a los habitantes de Comala. En vida, Pedro Páramo no quiso mediar con nadie porque quería abarcarlo todo. Después de hacerlo se convierte en el único 
proveedor de Comala. Pedro Páramo no puede ser considerado un cacique, sino un anti cacique, aquel cuya mediación le sirve a él mismo. El anti caciquismo de Pedro Páramo no es, por supuesto, la negación de la figura del cacique tradicional sino acaso su intensificación que lo anula como mediador y lo convierte en Uno. No es coincidencia que algunos, como Ericka Beckman, vean en Pedro Páramo un heredero directo de otro Uno: Porfirio Díaz:

We can begin by noting that Pedro Páramo is a character made possible by uneven and combined development. He is the unique creation of the regime of Porfirio Díaz (1876-1910), the period of Mexican history immediately preceding the Revolution that witnessed an unprecedented opening of the country to foreign capital, and with it, the vast enclosure of previously common lands. (Beckman 817)

Deborah Cohn también coincide en este análisis en donde el cacique aparece más bien como creación y no como creador; como acumulador y no como innovador; como parálisis al que todo se le ha legado:

The cacique is part of an entrenched system of landownership, a semifeudal system in place since the early years of the colonial period. The consolidation of his land and fortune can be dated through internal evidence to the years of Porfirio Díaz's regime, notorious for facilitating the expansion of large estates. (Cohn 262)

Las últimas novelas de Carlos Fuentes lidian con el problema de un caos ordenado. Ordenado desde el capitalismo (Max Monroy); el imperio norteamericano como marca política global que reduce a nada el poder mexicano (La silla del águila); el del crimen como estándar (Adán en Edén). En cambio, Pedro Páramo es la representación de un orden caótico cuyas señas internas (los murmullos, los ecos, la muerte) son el resultado de un poder desbocado y asesino 
CATEDRAL TOMADA: Revista de crítica literaria latinoamericana / Journal of Latin American Literary Criticism De la comunión política a la fragmentación estatal: crimen, ley y soberanía en Carlos Fuentes y Juan Rulfo.

que todo lo fragmenta pero que también contiene esa fragmentación en la excepción legal y mortal en la que mantiene a Comala. El anti cacique Pedro Páramo encuentra su doble invertido en los verdaderos caciques contemporáneos: Max Monroy, Nicolás Valdivia (La silla del águila), Adán Góngora (Adán en Edén). Pedro Páramo no tiene que mediar ante y para nadie porque él satura el poder. En la novelística tardía de Carlos Fuentes, en cambio, los polos varios del poder globalizado y nacional requiere de intermediarios que traduzcan en pactos políticos las políticas públicas o incentivos fiscales que los múltiples grupos demandan en este nuevo orden atravesado por arreglos transnacionales y un sistema multiplicado y multiforme. A los verdaderos caciques, al contrario de Pedro Páramo, les importa mucho la ley, aunque sea su apariencia.

El verdadero poder no es aquel que se ejerce sin limitaciones sino aquel que, no ejerciéndose, mata. El gesto más conocido en toda la historia humana de un poder así lo ejerció Poncio Pilatos, el cual, lavándose las manos, renuncia a su poder para transferirlo al pueblo. Pedro Páramo también renuncia, de alguna manera, a su poder o, más bien, lo transforma en pasividad, conteniéndolo para sí mismo, el reverso de lo que hasta ese momento había sido. La formalidad de Pilatos fue lavarse las manos; la de Pedro Páramo, esconderse en una cobija. Al no salvar a Jesús, Pilatos contribuye a crear una religión milenaria; al no hacer nada por Comala, Pedro Páramo contribuye a inmortalizarla. A ambos gestos los une el acto revolucionario de trastocar la coraza del poder para dejarlo en su esencia. Lo verdaderamente importante, sin embargo, no es si Jesús o Comala realmente murieron, sino si después de muertos regresaron a la vida. Solo la fe o la imaginación tienen la respuesta. ¿No es un acto maravilloso unir fe y ficción como si fueran el anverso y el reverso de un mismo fenómeno, es decir, la certeza de una muerte anunciada? A Páramo y a Pilatos los une la renuncia del poder ante colectividades que por error (Pedro Páramo) o por venganza (los que deciden elegir a Barrabás) se convierten en los receptáculos últimos de un poder corrompido. Pedro Páramo, el no cacique, el no mediador, el no facilitador. Es Comala tiempo detenido y también lo Uno, lo indiferenciado, un México podrido 
desde la raíz, infectado por las promesas rotas de la modernidad, desolado, solitario, incapaz. "Pedro Páramo es el propio pueblo (sus habitantes), y la mejor prueba de ello es que cuando él decide cruzarse de brazos condena a muerte a Comala" (Rodríguez 627).

A la inversa de Octavio Paz: somos contemporáneos de todos los muertos, lavando, una y otra vez, la plaza de los sacrificios. Al contrario del debilitamiento estatal representado en las últimas novelas de Carlos Fuentes, Comala es un hoyo negro, una especie de Estado controlado por la disciplina del anti cacique. Y es que Pedro Páramo, emergencia legal continuada, soberano que inocula el poder e inmuniza cualquier intento democrático de apertura, se encuentra atado a la tierra y al tiempo para no dejarlos ir:

Land and cacique alike are immobilized. And, as we have seen, nor can the novel itself unfold and move beyond the scene. Rather, it comes back and time and again to the moment of Susana San Juan's death, which is telescoped into that of the cacique and that of Comala, and which serves as its own ending. Clocks might continue to tick, then, but in Pedro Paramo's world, there is no progress or true change. Every one of his actions is a reenactment of the past or an attempt to exorcise it, and everyone is condemned to fail, returning him full circle to the vivid sensation of loss. (Cohn 261)

El poder de Pedro Páramo es reafirmado por medio de la voz: órdenes escuetas, directas, sin asomo de dudas. Pedro Páramo es la voz de voces en un mundo atravesado por lamentables murmullos y ecos. La última orden que da se la da a sí mismo ("me cruzaré de brazos y Comala se morirá de hambre"), envolviendo en un bucle su propia autoridad, ahora perteneciente a él para toda la eternidad. Comala muere de hambre no porque Pedro Páramo la mate de hambre sino porque la deja morir. Y no solo eso: también porque deja de ordenar. Cuando se clausura su autoridad y se auto inmuniza también se acaba y se cierra el mundo 
CATEDRAL Tomada: Revista de crítica literaria latinoamericana / Journal of Latin American Literary Criticism De la comunión política a la fragmentación estatal: crimen, ley y soberanía en Carlos Fuentes y Juan Rulfo.

de las posibilidades: no sabemos cuándo empieza Comala aunque podríamos estar seguros que acaba cuando Pedro Páramo muere. Ahora, Comala "es un lugar sin lugar" (Hernández 620), que existe en un "universo cerrado y atemporal” (620). La presencia de Pedro Páramo es lo que satura Comala y la cierra sobre sí misma. Esto provoca que las únicas formas de resistencia sean extremas y acaso contradictorias: ya sea el parricidio (Abundio Martínez), el incesto (los hermanos) o la locura (Susana San Juan). Con su acción, Abundio Martínez precipita la decadencia de Comala hacia lo Uno; con su locura, Susana San Juan resiste a Pedro Páramo pero se cierra sobre sí misma, precipitando y fortaleciendo las nociones de lo Uno, lo Mismo, que el anti cacique continúa con su reinado.

Una lectura contemporánea de Pedro Páramo atraerá a su órbita factores indudablemente vinculados a la crisis de seguridad en México, como lo hace Alberto Ribas Casayas y para el cual el poder de Pedro Páramo se sustenta sobre "la gestión de dos poderes que se alimentan mutuamente, el poder necropolítico y el dominio por la deuda" (Ribas 60), dos expresiones perversas de un capitalismo necrotizado por la violencia y la ganancia y cuyas estructuras operativas asimilaron diversos procesos presentes en el estado mexicano desde tiempo atrás: corrupción, impunidad, ineficiencia. A las viejas formas del poder hay que añadir otra más, basada en la violencia y la muerte, el necropoder: "Entendemos por necropoder la apropiación y aplicación de las tecnologías gubernamentales de la biopolítica para subyugar los cuerpos y las poblaciones que integra como elemento fundamental la sobreespecialiación de la violencia y tiene como fin comerciar con el proceso de dar muerte" (Valencia 160). Estos nuevos actores necroempoderados son representados en la novela como inversiones de emprendedores que buscan escalar en la pirámide social por medio de la innovación, la disciplina y la creatividad. En su lugar, los nuevos valores son los de la violencia, el arribismo, la dominación.

En La voluntad y la fortuna el necroempoderamiento se hace invisible detrás de estructuras de poder que lo sostienen, como el imperio de Max Monroy o el dinero de Nazario Esparza. Lejos de debilitar su representación, Fuentes la 
fortalece, pues expone la manera en que el necrocapitalismo se adhiere a estructuras legales que aprovecha para desplazar al Estado pero manteniendo, formalmente, la geometría gubernamental. La novela representa el surgimiento de áreas criminales camufladas al interior de la ley. Tanto las fortunas de Monroy como de Esparza están atadas a estructurales criminales: la del primero a través de su secretaria Asunta Jordán, a su vez cómplice de una banda criminal que acaba por exterminar a Josué; la del segundo a través del testimonio de su propio hijo en una conversación con su madre respecto a la fortuna de Nazario Esparza “Esfuerzo? ¿Así se llama ahora el crimen?” (Fuentes 353). Todo presentado bajo la fachada de la legalidad. La operatividad del crimen actúa bajo formas fantasmales. Como nos recuerda Reguillo:

La máquina narco es un fantasma. Su dominio deriva de ocupar un espacio insimbolizable (en el sentido freudiano) deslocalizado, que apela y despierta las más profundas fisuras entre lo que concebimos como real y los temores que se dislocan. La imposibilidad de la simbolización trabaja en el imaginario, en la obturación de cualquier posibilidad de significación. La máquina narco es ubicua, elusiva, fantasmagórica y permanece ahí, por más que aparezcan y sean —momentáneamentesometidos, sus criados. (Reguillo)

Máquina fantasma que adquiere formas ultraespecializadas de violencia. Por ello, la lectura de Ribas es correcta en cuanto a que Pedro Páramo adquiere una nueva actualidad debido a su conexión con la actual violencia mexicana. Me parece, sin embargo, que La voluntad y la fortuna refleja de manera más consistente el necropoder como un orden tras las sombras que, a pesar de su espectacularidad, busca mantenerse como parapoder y no como centro único de decisión. Y es que casi cualquier ciudad o geografía mexicana contemporánea que ha sido invadida y necrotizada por corporaciones criminales aliadas con ciertos sectores del Estado mexicano - hablar únicamente de narcotráfico oscurece el 
CATEDRAL Tomada: Revista de crítica literaria latinoamericana / Journal of Latin American Literary Criticism De la comunión política a la fragmentación estatal: crimen, ley y soberanía en Carlos Fuentes y Juan Rulfo.

fenómeno - actúa como territorio de guerra ocupado por bandas cada vez más fragmentadas e irreconocibles: el legado de la guerra contra las drogas del presidente Calderón fue el de desmantelar los grandes carteles sin advertir que estas nuevos organismos criminales formarían sus propias formas de utopía: es decir, las criminotopías mexicanas en donde amplios sectores territoriales pertenecen al crimen. Las formas en las que se concretan estas necroutopías son el asesinato serializado de mujeres, la extorsión y el secuestro, los cuerpos tirados en vías públicas, la tortura. Estas expresiones violentas, sin embargo, no operan en la superficie ya que se encuentran oscurecidas por toda una industria del espectáculo y la banalidad que a modo de interrupción penetra y codifica a la violencia como un más allá fuera de nuestras vidas. Este espectáculo ha llegado incluso a instalarse en las fuentes primordiales del poder mexicano, como la Presidencia de la República. Carlos Fuentes se asoma al abismo necrosoberano a vuelo de pájaro y lo señala. No le interesa tanto explayarse en sus detalles sino más bien su funcionamiento: el escritor mexicano nos revela los procesos de la máquina y su conformación por y a partir de la muerte. La plurisoberanía estatal y criminal no admite fronteras y ambas formas de poder se alimentan a sí mismas.

La violencia como catacresis y lenguaje común cuya escritura se ha normalizado bajo un léxico cada vez más extendido:

Ejecutados (nombre genérico para todos los muertos de y por la máquina); ahorcados (modalidad en la ejecución, alude a un final específico pero ambiguo); colgados (modalidad en la ejecución, principalmente vista en el norte), decapitados (modalidad, nombra de manera fantasmagórica los hallazgos de cuerpos incompletos); encajuelados (cadáveres que "aparecen" en las cajuelas de autos abandonados); deslenguados (cuerpos a los que se les ha arrebatado el habla); encobijados (cuerpos que se "entregan"paradójicamente - en cobijas o mantas que deberían servirían para proteger; entambados (cuerpos que "aparecen" o no aparecen porque han 
sido disueltos en ácido); embolsados (cuerpos que se "entregan" en bolsas negras, para basura); las hieleras (cabezas que se encuentran en recipientes o "cajas" para almacenar hielo). (Reguillo)

Se lexicaliza la violencia porque se busca representarla mediante un diccionario de retóricas múltiples que abarquen el fenómeno. Las narrativas, sin embargo, no alcanzan a representar ni mucho menos a explicar lo que ocurre en franjas territoriales doblegadas e imbricadas cada vez más con el crimen.

Si bien en Pedro Páramo no encontramos las nuevas maneras espectaculares de la violencia, sí que vemos un poder que todo lo absorbe para integrarlo en un vacío. "En Comala encontramos también el ejercicio de un poder tiránico que lleva a la descomposición de comunidades, la depauperación de individuos y la desaparición de la vida que implica una especie de apocalipsis local” (Ribas 66). No solo en Comala este proceso aparece como una forma de implosión provocada por la indistinción entre crimen y ley que llevan a un poder soberano sin control, sino también en La voluntad y la fortuna. Las formas de poder, sin embargo, son diversas. Si en Comala todo cabe dentro de la voluntad de Pedro Páramo, en el México de Carlos Fuentes la ausencia de autoridad llega a extremos irrisorios en donde el poder disciplinar del Estado se ha subjetivizado, personalizándose y biopolitizándose de modo individual, como cuando Miguel Aparecido, un personaje de la novela, decide auto encerrarse a sí mismo sin que ninguna autoridad se lo impida. La falta de comunicación gubernamental con lo social se da por supuesta. Ahora, el caso es mucho más extremo, pues la desconexión gubernativa es del gobierno...con el propio gobierno, que no es ni siquiera capaz de administrar a sus propios presos. El paso que va del poder soberano de Pedro Páramo a la corporativización, multiplicidad y fragmentación criminal del poder en La voluntad y la fortuna es tal que si Pedro Páramo decidiera cruzarse de brazos en una Comala localizada en cualquier pueblo mexicano, Comala no moriría de hambre sino que sería cooptada por bandas necrocriminales con objetivos indiscernibles, quizá dedicadas al robo, al secuestro, a la extorsión, al 
CATEDRAL TOMADA: Revista de crítica literaria latinoamericana / Journal of Latin American Literary Criticism De la comunión política a la fragmentación estatal: crimen, ley y soberanía en Carlos Fuentes y Juan Rulfo.

homicidio o al asesinato serializado. "El ejercicio del poder en Pedro Páramo, localizado y personalista, contrasta con los más desterritorializados y despersonalizados ejercicios del poder financiero, extractivo y/o criminal en el neoliberalismo contemporáneo" (Ribas 79). Esta despersonalización del poder ocurre en el México actual bajo las sombras de capos efímeros que aterrorizan a la población. En La voluntad y la fortuna cobra vida en la cárcel ficticia de San Juan de Aragón, en donde ningún poder discernible - ¿acaso el de Miguel Aparecido?- elige quién entra y quién sale de una de las instituciones estatales más paradigmáticas. Fuentes nos quiere decir que el caos gubernamental es tan grande que ni siquiera el Estado contabiliza a sus presos.

\section{De Rulfo a Fuentes}

Otros temas merecen la atención en este artículo, como el caso del incesto en Pedro Páramo pues nos ayuda a caracterizar, desde otro punto de vista, la pregunta del poder.

Detengámonos solo por un momento, pues, en esta cuestión. Anthony Stanton, sigue a Claude Lévi-Strauss, el cual dice que el incesto, más que una prohibición moral, era visto como socialmente absurdo ya que el matrimonio "es una institución de intercambio entre grupos que no están relacionado biológicamente" (Stanton 572). El incesto cerraba a la comunidad en sí misma en lugar de abrirla. Así, el tabú del incesto "exige que los elementos internos de la familia nuclear (elementos que son relacionales y no autónomos) sigan diferenciados y que otros elementos biológicamente externos entren en el sistema" (573). La transgresión que realiza el incesto es el paso entre la "naturaleza a la cultura" (573). Los hermanos en Pedro Páramo se encuentran transgrediendo ese orden social lleno de catolicismo y moralidad, al grado de que la hermana no puede sino expresar mediante ambigüedades aquello que le hizo el hermano. Sin embargo, la transgresión aquí también opera como complacencia, 
porque si Pedro Páramo es lo Uno, lo Mismo, el incesto sigue por ese mismo camino ya que representa una cerrazón familiar sobre una cerrazón social (Comala) transformando el incesto en Uno, lo Mismo. Pedro Páramo pretende homogeneizar su poder, al igual que el Estado mexicano durante el siglo XX (mediante el artículo 27 constitucional), a través de la apropiación indiscriminada de todo lo que yace bajo sus pies. La apropiación telúrica y lacustre y sexual y política de Pedro Páramo inmovilizan a Comala y la suspenden en un estado de emergencia continuo viviendo bajo la excepcionalidad de su anti cacique que nada permite que se mueva. Imposible no pensar en Pierre Clastres para conceptualizar lo que representa Pedro Páramo:

El Estado se pretende y se autoproclama centro de la sociedad, el todo del cuerpo social, el señor absoluto de los diversos órganos de ese cuerpo. Se descubre así, en el corazón mismo de la sustancia del Estado, la potencia actuante de lo Uno, la vocación de negación de lo múltiple, el horror a la diferencia. (Clastres 60)

El Estado, pues, lo pretende todo: lenguas, bienes, propiedades, ciudadanos, sistemas políticos que Fuentes y Rulfo describen de formas diversas pero iluminadoras y que van de la figura totalizadora de Pedro Páramo a los mercachifles intrascendentes y ganapanes oportunistas de Lorenzo Terán y Valentín Pedro Carrera. El verdadero poder y los caciques auténticos son aquellos que verdaderamente median entre procesos: Max Monroy o Nicolás Valdivia. El verdadero poder y el anti cacique auténtico es Pedro Páramo: aquel que logra suspender a todos con su muerte y su vida.

Así, pues, el hilo conductor entre Pedro Páramo y la última etapa novelística de Carlos Fuentes debe examinarse con más detenimiento por la crítica, especialmente porque las resonancias entre las novelas nos sirven como espacios diferenciadores que, desde la literatura, ayudan a resaltar las profundas diferencias que existen entre los textos y entre las distintas versiones del aparato 
CATEDRAL TOMADA: Revista de crítica literaria latinoamericana / Journal of Latin American Literary Criticism De la comunión política a la fragmentación estatal: crimen, ley y soberanía en Carlos Fuentes y Juan Rulfo.

estatal mexicano del siglo XX. México ha dejado de ser el país de las encrucijadas para convertirse en el país de las permanencias, ahora lo descubrimos, necesarias. Si hay una lección para llevarse a la cama sería la de pensar a México como un hombre cruzado de brazos desde su fundación: históricamente inmovilizados, las cuevas geológicas de nuestra memoria se concentran en la parálisis de la voluntad y el desgaste de nuestra fortuna como herencias directas de una forma particular de gobernar y de ser.

Suspendidos entre Comala y nuestra historia, las cesuras del poder nos llegan, a duras penas, como murmullos callados, riachuelos fúnebres, niebla compartida, rumores de viento doblegados...

\section{Bibliografía}

Beckman, Ericka. "Unfinished transitions: the dialects of rural modernization in Latin American Fiction". Modernism/ modernity, volume 23, number 4, Nov. 2016, pp. 813-832.

Boldy, Steven. "De la afrenta al melodrama: la familia, la violencia y el crimen en las últimas obras de Carlos Fuentes". Mexican Studies/Estudios mexicanos, vol. 28, Issue 2, summer 2012, pp. 243-263.

Clastres, Pierre. Investigaciones en antropología política. Gedisa, 1981.

Cohn, Deborah. "A wrinkle in Time: Time as structure and meaning in "Pedro Páramo”. Revista Hispánica Moderna, año 49, no.2, Dec.1996, pp. 256266.

Dove, Patrick. "Reflections on the origin: transculturation and tragedy in Pedro Páramo". Angelaki, 6:1, pp. 91-110.

Fuentes, Carlos. La voluntad y la fortuna. Kindle Edition, Alfaguara, 2016.

Hernández F. Jorge. Carlos Fuentes: Territorios del tiempo. Antología de entrevistas. Compilación e introducción de Jorge F. Hernández. Tierra Firme, Fondo de Cultura Económica, 1999.

Linz, Juan J. Totalitarian and Authoritarian Regimes. Lynne Rienner Publishers, 2000.

Rodríguez, Rafael. "El fin de la modernidad: Pedro Páramo y la desintegración de la comunidad". Bulletin of Hispanic Studies, LXXVIII (2001), pp. 619-634. 
Reguillo, Rosana. "La narcomaquina y el trabajo de la violencia: apuntes para su decodificación". Hemispheric Institute E-misférica, 8.2, 2011.

Ribas Casayas, Alberto. "El tirano indigente: Pedro Páramo, deuda y necropolítica". A contracorriente, vol. 14, num 3, Spring 2017, pp. 59-85.

Rodríguez, Rafael. "El fin de la modernidad: Pedro Páramo y la desintegración de la comunidad". Bulletin of Hispanic Studies, LXXVIII (2001), pp. 619-634.

Stanton, Anthony. "Estructuras antropológicas en Pedro Páramo". Nueva Revista de Filología Hispánica, t. 36, No. 1 (1988), pp. 567-606.

Valencia, Sayak. Capitalismo Gore. Ediciones Culturales Paidós, 2016.

Van Delden, Maarten. Carlos Fuentes, Mexico and Modernity. Vanderlbilt University Press, 1998.

Williams, Gareth. "The mexican exception: sovereigntiy, police and democracy". Palgrave MacMillan, 2011. 